\title{
Nucleation and Condensation of Magnesium Vapor in Argon Carrier
}

\author{
Jibiao Han ${ }^{1,2}$, Daxue Fu ${ }^{1,2}$, Junhua Guo ${ }^{1,2}$, Zonghui Ji ${ }^{1,2}$, Zhihe Dou ${ }^{1,2}$ and Ting'an Zhang 1,2,* \\ 1 School of Metallurgy, Northeastern University, Shenyang 110819, China; hanjibiaoa@163.com (J.H.); \\ fudx@smm.neu.edu.cn (D.F.); guojunhua92@163.com (J.G.); jzh965645152@163.com (Z.J.); \\ douzh@smm.neu.edu.cn (Z.D.) \\ 2 Key Laboratory of Ecological Metallurgy of Multi-Metal Intergrown Ores of Ministry of Education, \\ Shenyang 110819, China \\ * Correspondence: zta2000@163.net; Tel.: +86-24-8368-6283
}

Received: 31 August 2020; Accepted: 26 October 2020; Published: 29 October 2020

\begin{abstract}
The nucleation and condensation of Magnesium $(\mathrm{Mg})$ vapor carried by argon gas (Ar) were examined. The condensation of Mg vapor at a heat source temperature of 1273-1473 K and Ar flow rate of $0.1-0.4 \mathrm{~m}^{3} / \mathrm{h}$ was analyzed. The result indicated that the condensation temperature is affected by the heat source temperature and $\mathrm{Ar}$ flow rate, and the condensation temperature of $\mathrm{Mg}$ vapor was 1013.3 $\mathrm{K}$ at a heat source temperature of $1473 \mathrm{~K}$ and Ar flow rate of $0.2 \mathrm{~m}^{3} / \mathrm{h}$. The effects of $\mathrm{Mg}$ vapor partial pressure and temperature of the condensation zone on the nucleation and condensation of $\mathrm{Mg}$ vapor carried by Ar were calculated and analyzed in terms of atomic collisions and critical nucleation radius. Increased vapor oversaturation and decreased condensation temperature were favorable for liquid nucleation growth. The $\mathrm{Mg}$ condensation products in Ar flow rate of $0.2 \mathrm{~m}^{3} / \mathrm{h}$ at a heat source temperature of $1473 \mathrm{~K}$ were analyzed by XRD, SEM, and EDS, which indicated that the condensed product was of high purity and not easily oxidized in Ar flow. In this paper, the quality of Mg vapor condensation was controlled, which provided the theoretical and experimental basis for a continuous Mg production process.
\end{abstract}

Keywords: magnesium vapor; condensation; nucleation; Ar carrier

\section{Introduction}

Magnesium (Mg) is one of the lightest structural metal materials. Due to its low density and high strength, its alloys are widely used in the automobile industry, electronics, aerospace, and other important fields [1-3]. The main production methods for $\mathrm{Mg}$ in the world are thermal reduction and molten salt electrolysis of $\mathrm{MgCl}_{2}$ [4,5]. In the thermal reduction process, the Pidgeon process has become the main method because of its mature and simple process and low cost [6]. More than $80 \%$ of the world's Mg metal is produced by the Pidgeon process in China [7]. However, this process is divided into separate calcination and reduction steps; the production process is taken in vacuum conditions. The vacuum needs to be removed after the reduction, so it is not possible to produce continuously $[8,9]$. This problem has received much research attention in recent years, and a continuous Mg production process has become a research hotspot.

Zhang et al. have combined calcination and reduction steps to study the kinetics of a one-step $\mathrm{Mg}$ reduction by experiment and simulation. They obtained a result that the one-step $\mathrm{Mg}$ reduction production process can reduce reduction time and save energy [10-13]. Fu et al. studied the thermodynamics and kinetics of the integration process of calcination and reduction and found that canceling the calcination process can greatly save energy [14-18]. These studies rely on reducing calcination to achieve continuous production of $\mathrm{Mg}$. Other researchers used an inert gas to replace 
the vacuum state. For example, Morsi studied the kinetics of the Mg process by using a silicothermic reduction process at $1 \mathrm{~L} / \mathrm{min}$ argon (Ar) flow and found that the pellet reduction rate was up to $92 \%$ in an Ar atmosphere [19,20]. Further kinetics analyses of Mg production in Ar have been performed by Wulandari [21] and Chen [22]. Zhang et al. presented a continuous magnesium production method by combining the method of calcination and reduction. Dolomite or magnesite is added with ferrosilicon and calcium fluoride to make pellets, which are calcined at $1123-1323 \mathrm{~K}$ in the argon flow. The calcined high temperature pellets are directly reduced at 1473-1873 K without cooling in the protection of argon, and then the magnesium vapor is carried by argon and condensed in the condenser; this method can greatly shorten the $\mathrm{Mg}$ production cycle and achieve the goal of continuous production combined method of calcination and reduction [23]. These results indicated that $\mathrm{Mg}$ reduction in $\mathrm{Ar}$ was feasible and offered a nonvacuum $\mathrm{Mg}$ production technology with low energy consumption and high efficiency.

$\mathrm{Mg}$ is highly reactive, so it is necessary to carry $\mathrm{Mg}$ vapor generated by reduction reactions to the condensation zone for condensation in an inert gas, which can realize continuous $\mathrm{Mg}$ production. Therefore, $\mathrm{Mg}$ vapor condensation in an inert gas is important in continuous $\mathrm{Mg}$ production. Nucleation plays a decisive role in crystallization and condensation of the initial stage of metal vapor condensation [24]. Through simulation and experimental studies, Xiong et al. have concluded that the condensation temperature of $\mathrm{Mg}$ metal in vacuum conditions was $603-733 \mathrm{~K}$ and that the higher the temperature in the condensation zone is, the better the condensation quality [25-27]. Yang analyzed the theory of $\mathrm{Mg}$ vapor nucleation and growth during the vacuum process from a carbothermal reduction and found that crystallization quality is improved by increasing the $\mathrm{Mg}$ partial pressure under appropriate condensation temperature and temperature gradient [28]. Izmailov studied the statistical significance of nucleation [29], Leubner established particle nucleation and growth model [30], Ring studied nanometer cluster nucleation [31], and Lummen used molecular dynamics simulations to study uniform nucleation of supersaturated iron vapor [32], all of their result show the importance of vapor nucleation condensation.

Therefore, based on the theory of micro-atomic collisions and the critical nucleation radius, the condensation nucleation and growth of $\mathrm{Mg}$ vapor were analyzed in this paper. The condensation behavior of $\mathrm{Mg}$ vapor at $1273-1473 \mathrm{~K}$ and $0.1-0.4 \mathrm{~m}^{3} / \mathrm{h}$ Ar flow was studied using $\mathrm{Mg}$ as the raw material. The functional relationship between the heating temperature and condensation temperature of $\mathrm{Mg}$ vapor was obtained and the influence of temperature and partial pressure on $\mathrm{Mg}$ vapor condensation was analyzed. The relationships between the number of atomic collisions, critical nucleation radius, and $\mathrm{Mg}$ deformation and nucleation growth were obtained. The microstructures of $\mathrm{Mg}$ vapor condensation products were also observed. From the resulting theoretical and experimental data, the nucleation growth of $\mathrm{Mg}$ vapor in an inert gas was studied. The improved conditions for $\mathrm{Mg}$ condensation and growth were obtained, which provided a theoretical and experimental basis for $\mathrm{Mg}$ vapor condensation in an Ar flow.

\section{Experimental Method}

\subsection{Experimental Setup}

The schematic diagram of $\mathrm{Mg}$ vapor condensation was shown in Figure 1. A vertical tube furnace (SK-G08165-L, Zhonghuan, Tianjing, China) was used as the experimental device, which consisted of a vertical $\mathrm{Al}_{2} \mathrm{O}_{3}$ tube, forming two regions, including the $\mathrm{Mg}$ evaporation zone and the $\mathrm{Mg}$ condensation zone. The $\mathrm{Mg}$ vapor evaporation rate was controlled by the heating temperature in the furnace heating zone. A graphite crucible (30 mm in radius and $100 \mathrm{~mm}$ in height) containing $\mathrm{Mg}$ (99.9\%) was placed in the center of the furnace. Ar as the inert gas $(99.999 \%)$ was introduced from the furnace bottom and evaporated $\mathrm{Mg}$ vapor was carried to the condensation area. A movable graphite foil ( $0.2 \mathrm{~mm}$ in thick) was placed inside the condensation area as the condenser, with the upper end of the graphite foil fixed with stainless steel foil, to collect the condensed $\mathrm{Mg}$ metal. All parts were connected by a combination of compression ports, KF fittings, and Viton O-rings fittings. Ar flow was controlled by a flowmeter. 


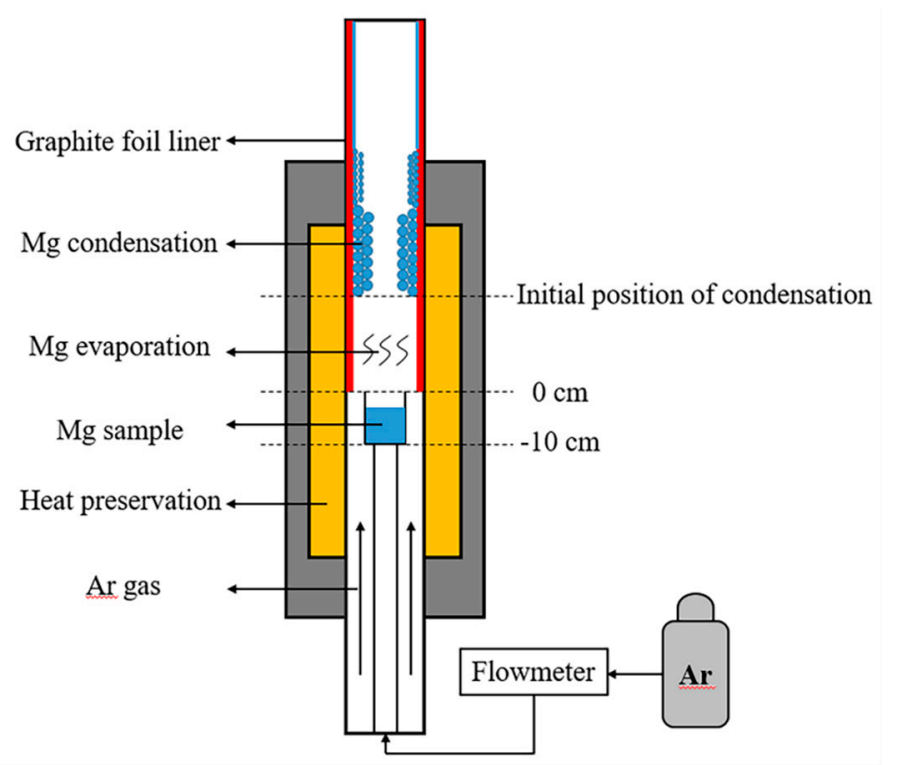

Figure 1. Schematic diagram of $\mathrm{Mg}$ vapor condensation.

\subsection{Experimental Procedure}

The heat source temperature of furnace was set at 1273-1473 K, which was measured by a fixed thermocouple and was controlled by the furnace control system. Furthermore, axial temperature gradient was measured by the movable thermocouple. The outlet pressure was measured by a vacuum pressure gauge, and the pressure was maintained at $1 \mathrm{~atm}$ during the experiment. After reaching the setting temperature, the furnace was purged with $0.2 \mathrm{~m}^{3} / \mathrm{h}$ Ar gas for $5 \mathrm{~min}$. A $25 \pm 0.5 \mathrm{~g} \mathrm{Mg}$ block in a graphite crucible was placed into the furnace for evaporation for $15 \mathrm{~min}$ at $0.1-0.4 \mathrm{~m}^{3} / \mathrm{h}$, then the furnace was cooled to $773 \mathrm{~K}$, the graphite paper was removed, and the crucible was weighed. The condensation position, condensation product temperature, and condensed $\mathrm{Mg}$ collected were assessed. The product was characterized by X-ray diffraction (XRD) (D8 Advance, Bruker, Karlsruhe, Germany), Scanning Electron Microscope (SEM) (Zeiss EVO 18, Carl Zeiss AG, Oberkochen, Germany) and Energy Dispersive Spectrometer (EDS) (Zeiss EVO 18, Carl Zeiss AG, Oberkochen, Germany).

\subsection{Physical Model}

Condensation is a typical nucleation process. Mg vapor condenses in argon due to the saturation temperature and accumulates on the solid wall. Because of the different temperature between inside and outside of the $\mathrm{Al}_{2} \mathrm{O}_{3}$ tube, the kinetic energy of the gas molecules is on the same order of magnitude as the van der Waals intermolecular forces. Collision of the vapor molecules causes the molecules to temporarily combine and to form clusters. Before the vapor condenses, the vapor molecules or atoms with low temperature form clusters due to the existence of supercooling and first form aggregates of a certain size. When the cluster reaches a critical size, the vapor, with a large number of agglomerates, collides and forms a deposition nucleation, and finally adsorbs on the tube wall. The agglomerates deposited on the wall still move along the condensation wall over a certain range due to the gas flow. During the movement, they collide with other clusters and grow, so the condensation nucleation and growth process proceed. Figure 2a shows the physical model of $\mathrm{Mg}$ vapor condensation. When $\mathrm{Ar}$ is mixed with $\mathrm{Mg}$ vapor, the increased inert gas prevents nucleation and growth and affects $\mathrm{Mg}$ droplet formation (Figure $2 b$ ). Clusters attach to the wall in a spherical shape because of interfacial tension. Ar can adsorb onto the surface to interfere with the movement of $\mathrm{Mg}$ agglomerates on the surface. In this case, the numbers of condensable vapor molecules in the gas phase are significantly reduced under the same conditions, such that the Ar affects $\mathrm{Mg}$ vapor condensation. Therefore, it was necessary to study the condensation nucleation and growth of $\mathrm{Mg}$ vapor carried by $\mathrm{Ar}$ gas. 


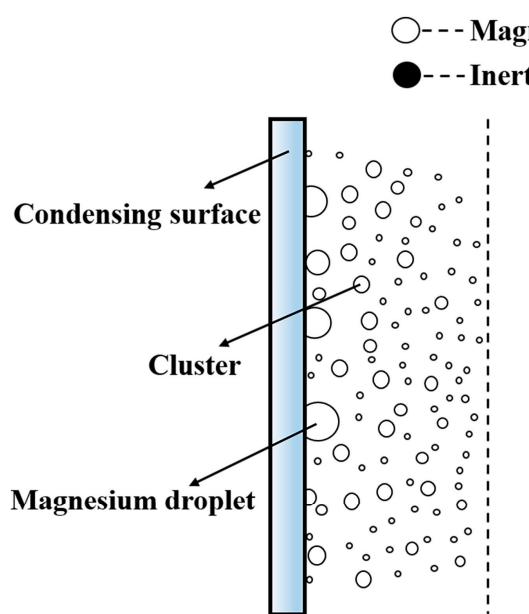

(a)

(b)

Figure 2. Physical model of $\mathrm{Mg}$ vapor condensation: (a) Magnesium vapor condenses without argon flow, (b) Magnesium vapor condenses with argon flow.

\section{Results and Discussion}

\subsection{Condensation of $\mathrm{Mg}$ Vapor at Different Temperatures and Gas Flow Rates}

$\mathrm{Mg}$ vapor was condensed at heat source temperature of $1273-1473 \mathrm{~K}$ and $0.2 \mathrm{~m}^{3} / \mathrm{h}$ Ar flow (Figure 3). As the axial distance from the heating source increased, the temperature decreased. The $\mathrm{Mg}$ vapor pressure was less than its saturation vapor pressure in the uncondensed zone, when the $\mathrm{Mg}$ vapor pressure was equal to the saturated vapor pressure, $\mathrm{Mg}$ vapor molecules was continuously collided with the condensation surface. After the energy loss, the molecular was absorbed on the condenser surface, surface atoms were gathered and grew continuously, and $\mathrm{Mg}$ vapor began to condense. The initial condensation temperature of $\mathrm{Mg}$ vapor was $\mathrm{T}_{\text {cond }}$.
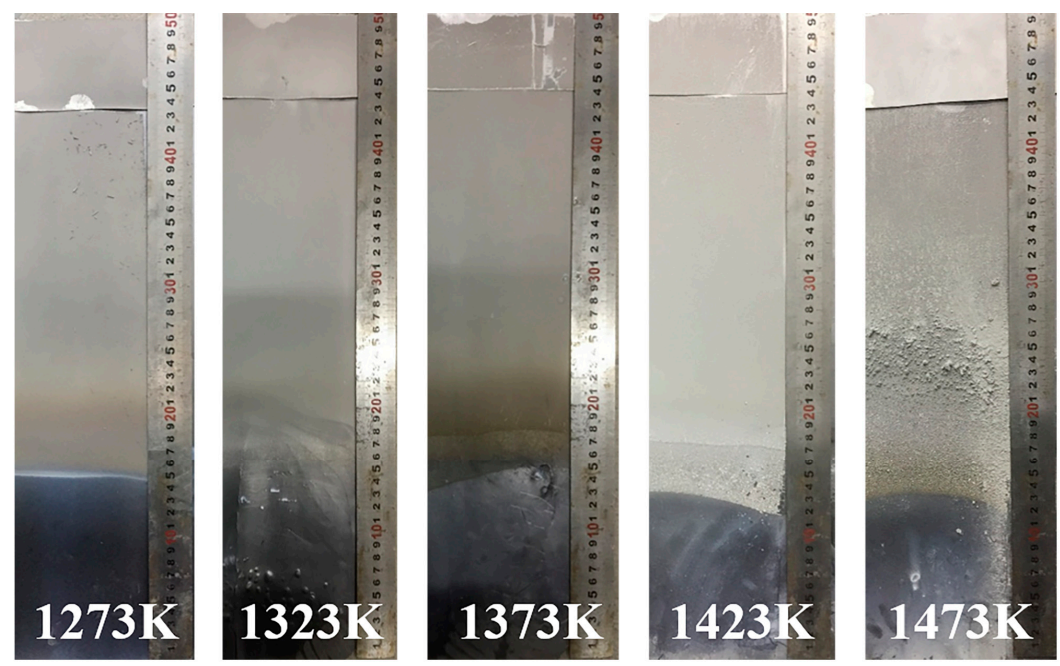

Figure 3. Condensation phenomenon of Mg vapor (1273-1473 K).

The Mg condensation behavior at heat source temperature of 1273-1473 K and Ar flow rate of $0.1-0.4 \mathrm{~m}^{3} / \mathrm{h}$ was studied in these experiments. The temperature distribution and condensation zone of the vertical furnace are shown in Figure 4. Mg vapor began to condense as the temperature of condensation zone decreased. Mg vapor at higher heating temperature was condensed at higher temperature of condensation zone, which was due to the higher temperature led to the higher energy and caused the molecules to evaporate violently, resulting in an increased $\mathrm{Mg}$ vapor partial pressure 
and a higher temperature condensation zone. $\mathrm{Mg}$ vapor with higher partial pressure reached saturated vapor pressure at condensation temperatures. Therefore the condensation occurred at a higher temperature; for example, $\mathrm{Mg}$ vapor was condensed at $1013.3 \mathrm{~K}$ with heat source temperature of $1473 \mathrm{~K}$ in Ar flow rate of $0.2 \mathrm{~m}^{3} / \mathrm{h}$, while it condensed at $976.7 \mathrm{~K}$ with $1423 \mathrm{~K}$ heating in $0.2 \mathrm{~m}^{3} / \mathrm{h} \mathrm{Ar}$. The initial temperature of condensation was different in different Ar flow rates at $1473 \mathrm{~K}$. When Ar flow increased, $\mathrm{Mg}$ partial pressure was reduced, and the initial condensation temperature was reduced. The initial condensation temperature was $1040.2 \mathrm{~K}$ at Ar flow rate of $0.1 \mathrm{~m}^{3} / \mathrm{h}$. However, when the Ar flow increased to $0.4 \mathrm{~m}^{3} / \mathrm{h}$, the condensation temperature decreased to $993.7 \mathrm{~K}$. Other temperatures followed the same rules. The above analysis showed that the condensation of magnesium was related to the partial pressure and the volatilization temperature of magnesium.
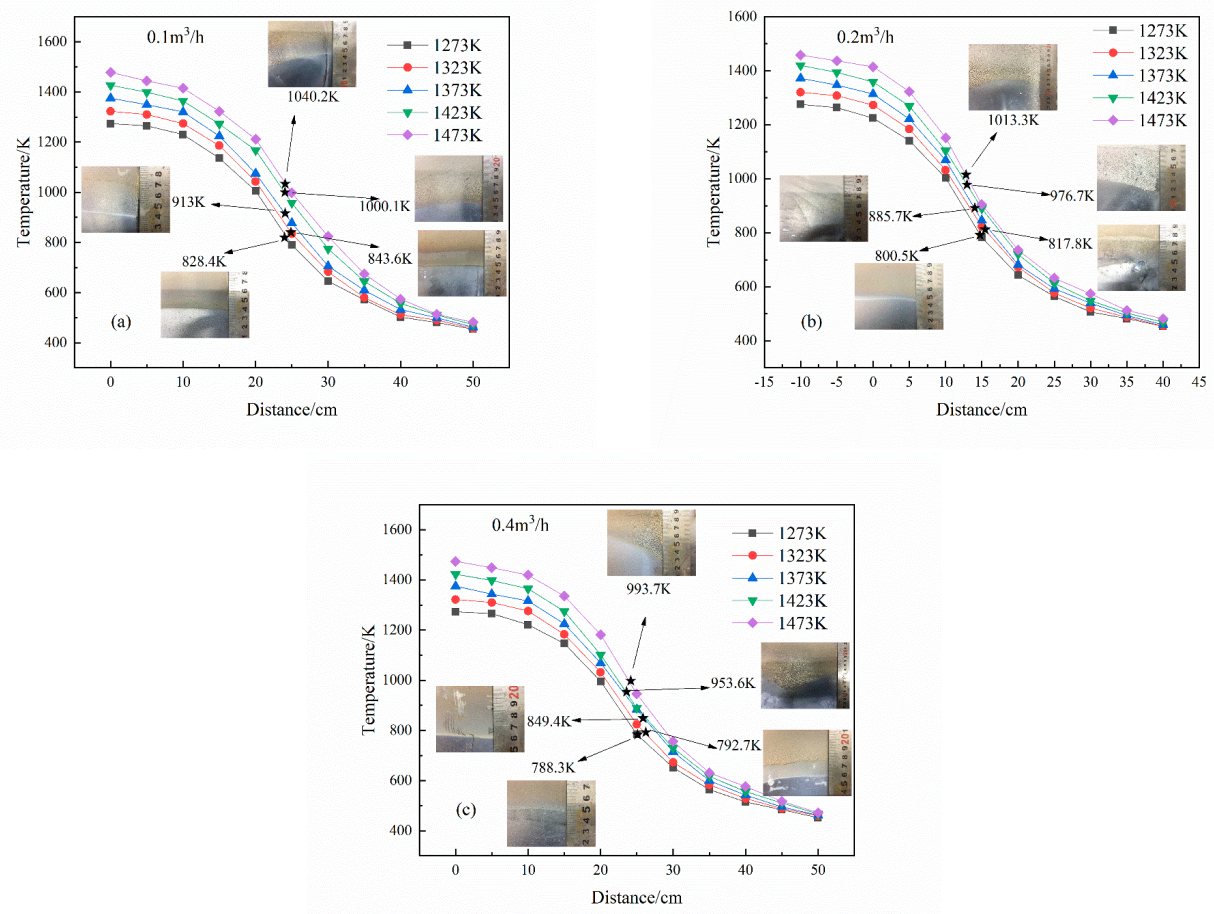

Figure 4. Relationship between temperature distribution and condensation position: (a) 1273-1473 K heating and $0.1 \mathrm{~m}^{3} / \mathrm{h} \mathrm{Ar}$, (b) 1273-1473 K heating and $0.2 \mathrm{~m}^{3} / \mathrm{h} \mathrm{Ar}$, (c) 1273-1473 $\mathrm{K}$ heating and $0.4 \mathrm{~m}^{3} / \mathrm{h}$ Ar.

As the $\mathrm{Mg}$ vapor condensation behavior was determined by the partial pressure, the $\mathrm{Mg}$ partial pressure at the corresponding condensation temperature was calculated. According to Clausius-Clapeyron equation, the saturated $\mathrm{Mg}$ vapor pressure formula at different temperatures was as [33]

$$
p_{M g}=10^{A T^{-1}+B l g T+C T+D}
$$

where $p_{M g}$ is the saturated vapor pressure of $\mathrm{Mg}$ metal, $\mathrm{Pa}$, and $\mathrm{T}$ is the temperature, $\mathrm{K}$.

The evaporation constants of $\mathrm{A}, \mathrm{B}, \mathrm{C}$, and $\mathrm{D}$ required in the calculation process are shown in Table 1, which can be found in references [34,35].

Table 1. Evaporation constant of $\mathrm{Mg}$.

\begin{tabular}{ccccc}
\hline A & B & C & D & Temperature Range (K) \\
\hline-7780 & -0.86 & - & 13.54 & $298-923$ \\
-7550 & -1.411 & - & 14.92 & $923-1393$ \\
\hline
\end{tabular}


The actual vapor pressure of magnesium is equal to its saturated vapor pressure at the beginning of condensation and higher than the saturated vapor pressure with the decrease of temperature. According to the condensation temperature of $\mathrm{Mg}$ vapor in different conditions, the vapor pressure at the condensation position was calculated. The influence of temperature and Ar flow on the condensation temperature and vapor pressure at the condensation point was shown in Figure 5. The red line is the pressure corresponding to $\mathrm{Mg}$ vapor condensation which is the saturated vapor pressure at the starting condensation temperature point. The vapor pressure of $\mathrm{Mg}$ vapor increased with the heating temperature increased while it decreased when the Ar flow increased. The high temperature led to the violent thermal movement of magnesium atoms and the increase of its energy, so magnesium atoms had a higher volatilization rate. The higher content of magnesium vapor in the mixed gas, the higher partial pressure, and the more magnesium vapor atoms were favorable for condensation and nucleation. Therefore, the gas-liquid phase transition occurred in the high temperature condensation zone. While the mass fraction of magnesium vapor decreased when the flow rate of argon increased, the phase transition temperature was reduced, which was consistent with the above analysis. The initial vapor pressure was only $21.1 \mathrm{~Pa}$ at Ar flow rate of $0.2 \mathrm{~m}^{3} / \mathrm{h}$ and heat source temperature of $1273 \mathrm{~K}$. When the heat source temperature reached $1473 \mathrm{~K}$, the vapor pressure increased to $1663.4 \mathrm{~Pa}$. When the initial vapor pressure of condensation was reduced to 15.1 $\mathrm{Pa}$ at Ar flow rate of $0.4 \mathrm{~m}^{3} / \mathrm{h}$ and heat source temperature of $1273 \mathrm{~K}$, the vapor pressure was $1219.0 \mathrm{~Pa}$ at $1473 \mathrm{~K}$. According to the law of gas-liquid phase transition, the increase of partial pressure of magnesium vapor would lead to the increase of condensation temperature inevitably. This phenomenon showed that temperature and partial pressure were important factors affecting the condensation of magnesium vapor.
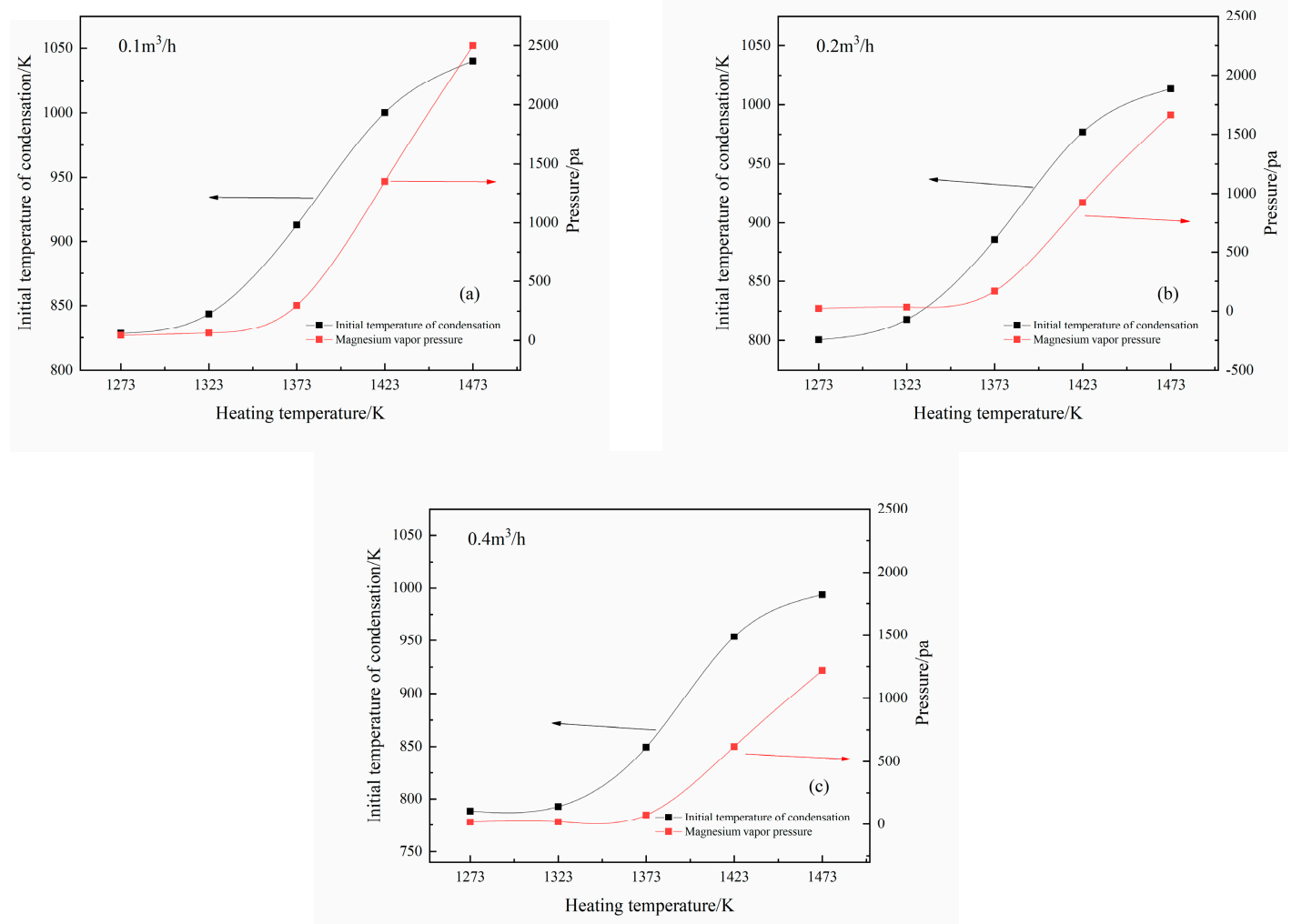

Figure 5. Effects of temperature and Ar flow on condensation temperature and vapor pressure at condensation point: (a) 1273-1473 K heating and $0.1 \mathrm{~m}^{3} / \mathrm{h} \mathrm{Ar}$, (b) $1273-1473 \mathrm{~K}$ heating, $0.2 \mathrm{~m}^{3} / \mathrm{h} \mathrm{Ar}$, (c) $1273-1473 \mathrm{~K}$ heating and $0.4 \mathrm{~m}^{3} / \mathrm{h}$ Ar. 


\subsection{Effects of Partial Pressure on $\mathrm{Mg}$ Vapor Condensation Nucleation}

The thermal motion and collisions of $\mathrm{Mg}$ vapor atoms are necessary conditions for gas nucleation and the number of collisions between atoms is the direct factor that affects the agglomeration and nucleation rate of $\mathrm{Mg}$ atoms [36]. The average number of atomic collisions was calculated as [37]

$$
Z=\sqrt{2} \pi d^{2} \bar{v} n
$$

where $n=\frac{k T}{P}$, and thus

$$
Z=\frac{\sqrt{2} \pi d^{2} \bar{v} P}{k T}
$$

where $Z$ is the number of collisions; $d$ is the atomic diameter of $\mathrm{Mg}$ vapor $\left(3.2 \times 10^{-10} \mathrm{~m}\right)$; $\bar{v}$ is the average atomic velocity, $\bar{v}=\sqrt{\frac{R T}{M}} ; M$ is the relative atomic mass of $\mathrm{Mg}\left(24.3050 \times 10^{-3} \mathrm{~kg} / \mathrm{mol}\right)$, $P$ is the vapor pressure at the initial position of condensation $(\mathrm{Pa})$; and $k$ is the Boltzmann constant $\left(1.38 \times 10^{-23} \mathrm{~J} / \mathrm{K}\right)$.

There were different $\mathrm{Mg}$ vapor pressures at different temperature distributions in the same conditions. When the metal vapor pressure generated by evaporation at the heat source temperature was $P_{1}$, the corresponding temperature was $T_{1}$. Furthermore, when the initial temperature of condensation was $P_{2}$, the corresponding temperature was $T_{2}$, as the formula [24]

$$
P_{1}=\frac{P_{2}}{T_{2}} T_{1}
$$

The experimental results and vapor pressure at the initial condensation zone were calculated using Formulas (1), (3) and (4). The relationship between temperature and the average collision times of $\mathrm{Mg}$ vapor was obtained (Figure 6).
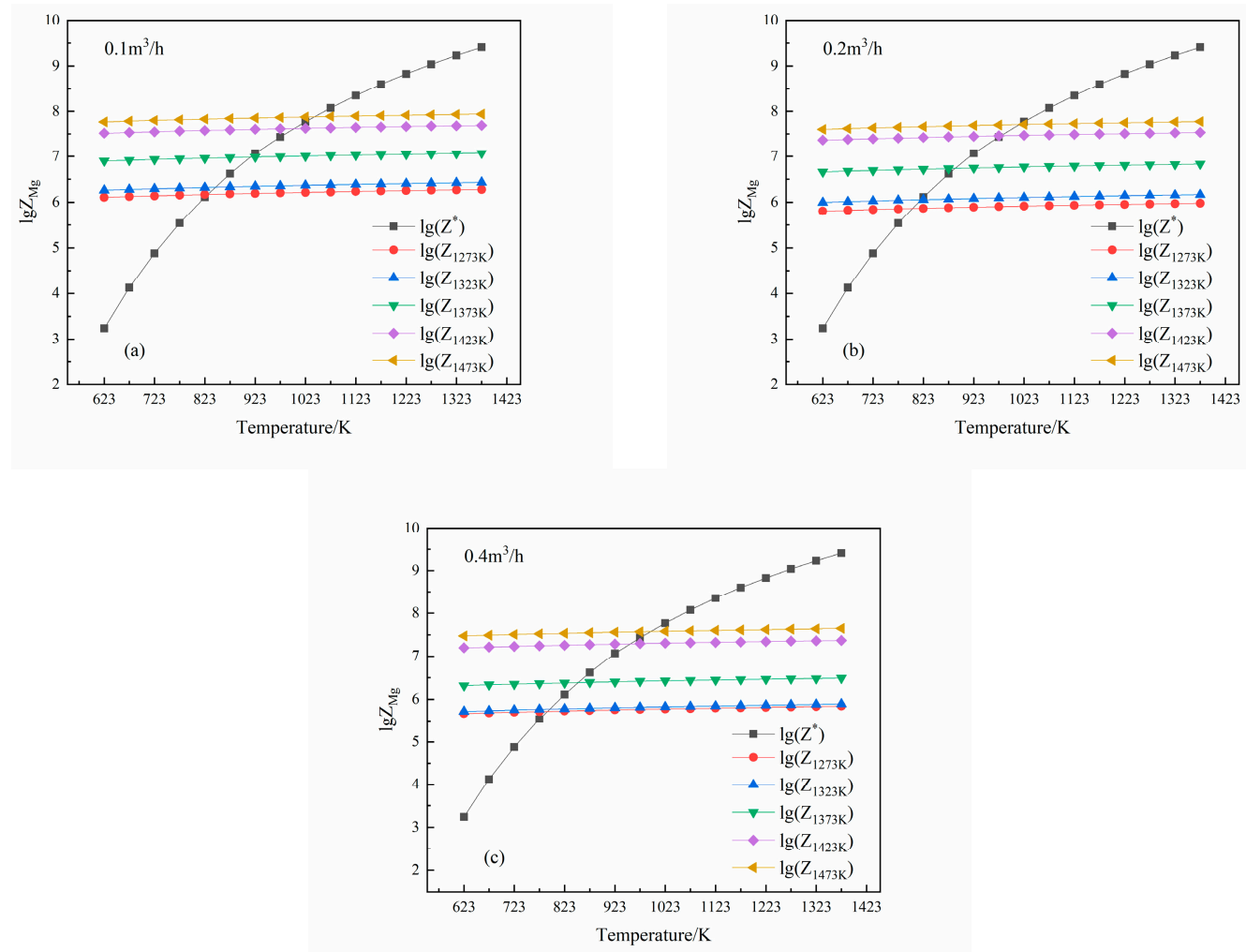

Figure 6. Relationship between temperature and average collision times of Mg vapor: (a) 1273-1473 K heating and $0.1 \mathrm{~m}^{3} / \mathrm{h} \mathrm{Ar}$, (b) $1273-1473 \mathrm{~K}$ heating and $0.2 \mathrm{~m}^{3} / \mathrm{h} \mathrm{Ar}$, (c) $1273-1473 \mathrm{~K}$ heating and $0.4 \mathrm{~m}^{3} / \mathrm{h} \mathrm{Ar}$. 
Taking the logarithm of the number of collisions in Figure $6, Z^{*}$ was the average number of atomic collisions corresponding to the standard saturated vapor pressure; $Z$ is the number of atomic collisions of $\mathrm{Mg}$ vapor at different temperature. The $\mathrm{Mg}$ atomic collision number at different temperatures increased exponentially with increased heat source temperature. Increased temperature resulted in intense atomic thermal motion, and the collisions were increased. As the atomic kinetic energy decreased with the condensation zone temperature decreased from 1473 to $623 \mathrm{~K}$ at $0.2 \mathrm{~m}^{3} / \mathrm{h}$ of Ar, the number of atomic collisions decreased from $6.14 \times 10^{7}$ to $2.88 \times 10^{7}$. When $P_{\mathrm{Mg}}$ was less than $\mathrm{P}^{*}$, which was to the right of the intersection of $\lg \left(Z^{*}\right)$ and $\lg (Z)$ (Figure 6), the $Z^{*}$ was more than $Z$, although the $\mathrm{Mg}$ vapor had greater kinetic energy and more collisions, it was less than the collisions of a saturated state of $\mathrm{Mg}$ vapor, which was conducive to $\mathrm{Mg}$ evaporation and not to aggregation. When $\mathrm{P}_{\mathrm{Mg}}$ was more than $\mathrm{P}^{*}$, the number of collisions was larger than the collision number in a saturated $\mathrm{Mg}$ vapor, and it was conducive to $\mathrm{Mg}$ vapor condensation. The difference between the collisions of $\mathrm{Mg}$ vapor and collisions in the saturated state was the driving force of nucleation. When collisions in $\mathrm{Mg}$ vapor and the saturation state were significantly different, magnesium vapor was condensed and nucleated rapidly when the temperature gradient was large. On the contrary, $\mathrm{Mg}$ vapor nucleated, collided, and slowly grew. Yang also analyzed the magnesium vapor in the vacuum condition of $40 \mathrm{~Pa}$, and if the condensing temperature is too low and $\mathrm{Z}$ reduces too fast, the rapid growth of the nucleation rate will result in a number of vapors nucleating simultaneously and condensing down; it is easy to get magnesium powder if magensium vapor is not in an extremely cold state and as $\mathrm{Z}$ slowly declines, magnesium vapor will go through a gas-liquid phase change [24], which is consistent with our analysis results. According to the theory of gas dynamics, a large number of atoms move irregularly when the mixture of magnesium vapor and argon flows, the average free path is used to express the distance of atom collision. The average free path of atoms is small when the partial pressure increases. The average number of collisions between atoms increases in unit time, and the atoms are easy to collide. Energy exchange occurs in the collision process, which makes the energy of atoms change and develop to a stable state. While there is no liquid core in the gas phase before nucleation, the liquid core appears and increases when the number of collisions increases, and the vapor atoms tend to condense. Besides collisions between $\mathrm{Mg}$ atoms, there are also collisions between atoms and the condensation wall. The direction of the gas molecules colliding on the solid surface is independent of the initial incident direction, and the molecules need to stay on the solid surface for a period of time before continuing to diffuse. This allows the gas molecules and container wall to have sufficient momentum and energy exchange, providing sufficient conditions for $\mathrm{Mg}$ vapor condensation and the formation of $\mathrm{Mg}$ atom liquid cores. These phenomena indicate that the partial pressure has a great influence on the condensation nucleation of magnesium vapor.

\subsection{Effects of Temperature on $\mathrm{Mg}$ Vapor Nucleation}

In the process of nucleation, although the life cycle of clusters is short, with the formation and decomposition of a large number of clusters, some clusters merge to the critical nucleation radius and condensation occurs spontaneously. From homogeneous nucleation, most liquid nuclei are spherical or hemispherical because of surface tension. According to the Kelvin equation [38]

$$
\ln \frac{P}{P^{*}}=\frac{2 \gamma V_{m}}{r_{k} R T}
$$

where $V_{m}=\frac{M}{\rho}$, the $\mathrm{Mg}$ critical nucleation radius $\mathrm{r}$, expressed as

$$
r_{k}=\frac{2 \gamma_{M g} M}{\rho R T \ln \left(\frac{P_{r}}{P^{*}}\right)}
$$

where $\gamma_{M g}$ is the surface tension coefficient of $\mathrm{Mg}$, $\rho$ is the liquid $\mathrm{Mg}$ density, $P_{r}$ is the surface vapor pressure $\left(P_{r}=P\right)$; and $P^{*}$ is the saturated $\mathrm{Mg}$ vapor pressure at the corresponding temperature. 
Here, $\gamma_{M g}$ was known from the literature as [39]

$$
\gamma_{M g}=721-0.149 T
$$

where $\rho$ was also known from the literature [40]

$$
\rho=1.834-2.647 \times 10^{-4} \mathrm{~T}
$$

Examining the experimental results, the density, surface tension, and temperature in Equation (6), the logarithm of the critical nucleation radius, and the calculated results of temperature were obtained (Figure 7). When $P_{r}$ was less than $P^{*}, \ln \left(\frac{P_{r}}{P^{*}}\right)$ was less than $0, r_{k}$ did not exist at this time, because the $\mathrm{Mg}$ vapor was not saturated and could not form a liquid core, which would have been conducive to the evaporation of $\mathrm{Mg}$ vapor. When the heat source temperature increased, the $\mathrm{Mg}$ vapor evaporation rate increased, resulting in increased vapor pressure. Therefore, the surface vapor pressure increased, the critical nucleation radius of $\mathrm{Mg}$ vapor decreased, and the number of atomic nucleations decreased. Thus, increase of heat source temperature was beneficial to $\mathrm{Mg}$ vapor condensation at a higher condensation temperature. Moreover, the gas phase with highly disordered structure has higher entropy, and the free energy of the liquid phase is higher than the gas phase at high temperature. The gas-liquid phase transition occurs when the free energy of liquid phase is lower than gas with the decrease of temperature, so the low temperature is conducive to metal nucleation. For any heat source temperature, with increased axial distance, the condensation zone temperature decreased, and the critical nucleation radius decreased. It was seen from Equation (9) that the number of atoms required for nucleation was also decreased. In the process of magnesium vapor movement with Ar flow, the temperature difference increased, which promoted the increase of driving force for nucleation, and then promoted nucleation.

$$
N=\frac{\frac{4}{3} \pi r_{k}^{3} \rho}{\frac{M}{N_{A}}}
$$
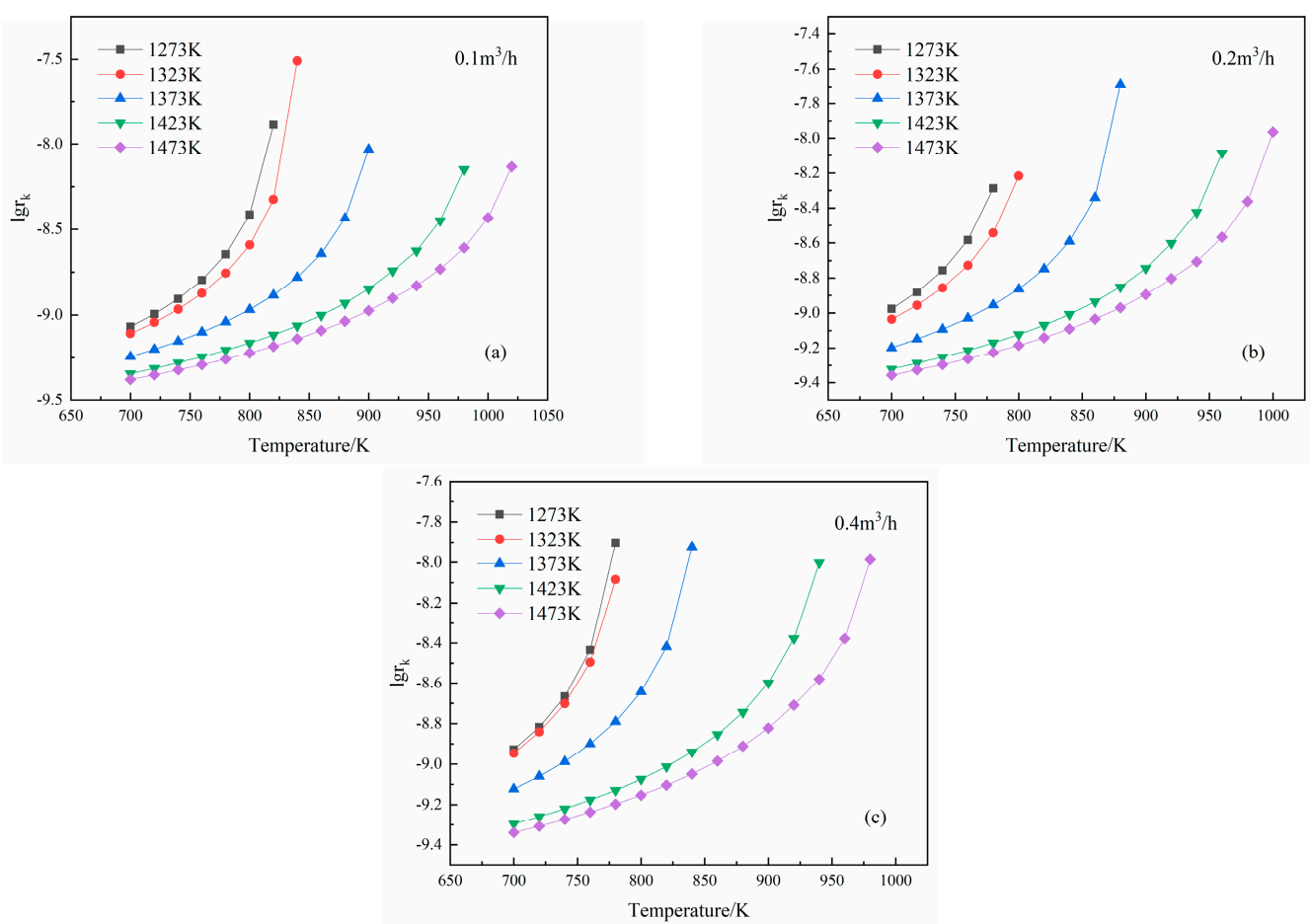

Figure 7. Relationship between the critical nucleation radius and temperature: (a) 1273-1473 K heating, $0.1 \mathrm{~m}^{3} / \mathrm{h}$ Ar, (b) $1273-1473 \mathrm{~K}$ heating, $0.2 \mathrm{~m}^{3} / \mathrm{h} \mathrm{Ar}$, (c) 1273-1473 K heating, $0.4 \mathrm{~m}^{3} / \mathrm{h}$ Ar. 
The critical nucleation radius and the number of atoms required for nucleation are listed in Table 2 at Ar flow rate of $0.2 \mathrm{~m}^{3} / \mathrm{h}$ and heat source temperature of $1473 \mathrm{~K}$.

Table 2. Nucleation radius and number of atoms required for nucleation (1473 K heating, $0.2 \mathrm{~m}^{3} / \mathrm{h} \mathrm{Ar}$, 900-1000 K).

\begin{tabular}{ccc}
\hline $\mathbf{T} / \mathbf{K}$ & $\mathbf{r}_{\mathbf{k}} / \mathbf{m}$ & $\mathbf{N}$ \\
\hline 1000 & $1.08543 \times 10^{-8}$ & $2.08105 \times 10^{5}$ \\
980 & $4.33604 \times 10^{-9}$ & $1.3311 \times 10^{4}$ \\
960 & $2.70944 \times 10^{-9}$ & $3.259 \times 10^{3}$ \\
940 & $1.97041 \times 10^{-9}$ & $1.258 \times 10^{3}$ \\
920 & $1.57239 \times 10^{-9}$ & $6.41 \times 10^{2}$ \\
900 & $1.27381 \times 10^{-9}$ & $3.42 \times 10^{2}$ \\
\hline
\end{tabular}

When the heat source temperature was $1473 \mathrm{~K}$ and the Ar flow rate was $0.2 \mathrm{~m}^{3} / \mathrm{h}$, the critical nucleation radius decreased from $1.09 \times 10^{-8}$ to $1.27 \times 10^{-9}$ from 1000 to $900 \mathrm{~K}$, which was decreased by nearly 10-fold. Furthermore, the number of nucleated atoms decreased from 208,105 to 342, the number of nucleating particles was larger than the critical number of nucleating particles, the liquid cores were in a stable state, and a large number of nucleation formed, which could obviously promote the nucleation and growth of magnesium vapor. While Tian calculated the nucleation radius in vacuum at 770-790 K as follow in Table 3, which was consistent with our results.

Table 3. Critical radii atoms contained in critical fluid core at different temperatures (770-790 K, $40 \mathrm{~Pa})[24]$.

\begin{tabular}{cc}
\hline $\mathbf{T} / \mathbf{K}$ & $\mathbf{r}_{\mathbf{k}} / \mathbf{m}$ \\
\hline 770 & $1.02 \times 10^{-8}$ \\
790 & $2.95 \times 10^{-9}$ \\
\hline
\end{tabular}

After a part of $\mathrm{Mg}$ vapor condensed, the thermal movement and collision of vapor atoms in the container did not stop, which provided conditions for the continuous growth of the liquid core, allowing the metal vapor to condense and grow into a spherical shape by surface tension. However, when the initial condensation temperature was less than $923 \mathrm{~K}$, a gas-solid phase transition occurred, which made it easier to form $\mathrm{Mg}$ powder. When the initial condensation temperature was higher than the melting point temperature, a gas-liquid-solid phase transition occurred, which allowed easy nucleation and growth [23].

\subsection{Condensation Phenomenon and SEM Analysis at Ar Flow Rate of $0.2 \mathrm{~m}^{3} / \mathrm{h}$ and Heat Source Temperature} of $1473 \mathrm{~K}$

The morphology and composition of Magnesium condensate were observed by XRD, EDS, and SEM were used. The analysis results were shown in the Figures 8 and 9. 


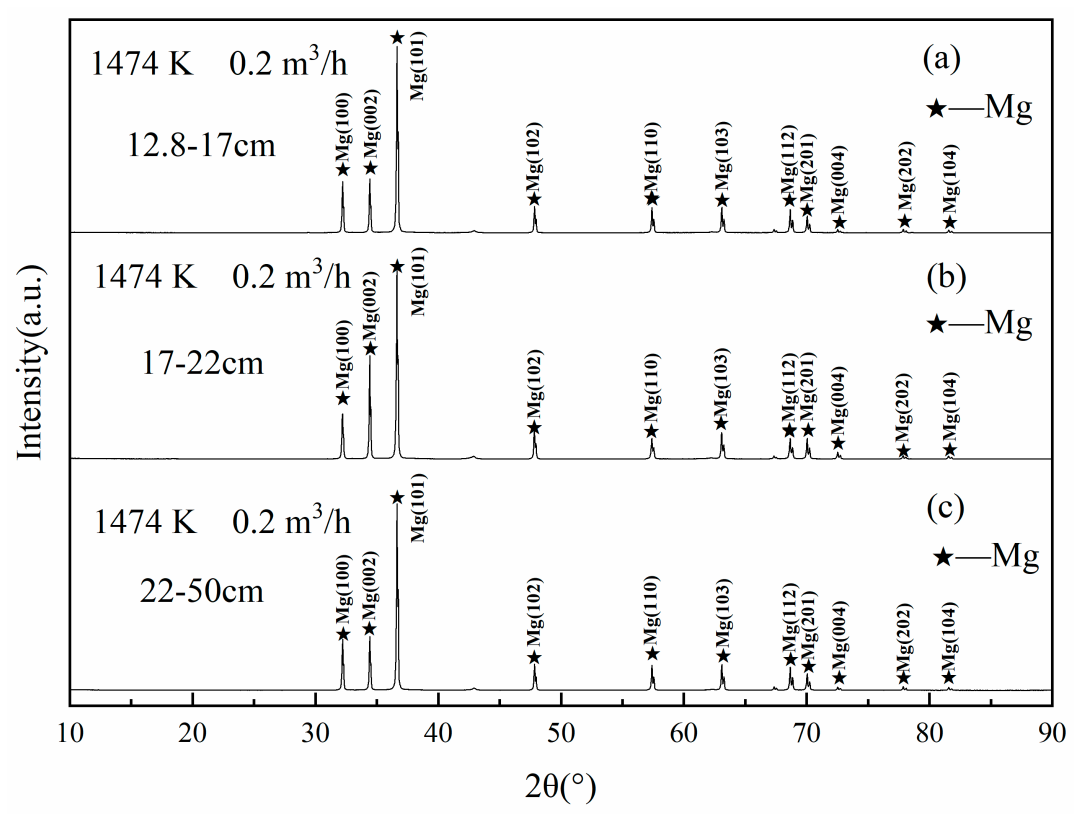

Figure 8. XRD analysis of magnesium condensation at different positions ( $1473 \mathrm{~K}$ heating and $0.2 \mathrm{~m}^{3} / \mathrm{h}$ Ar): (a) Mg product at $12.8-18 \mathrm{~cm},($ b) $\mathrm{Mg}$ product at $17-22 \mathrm{~cm},(\mathbf{c}) \mathrm{Mg}$ product at $22-50 \mathrm{~cm}$.

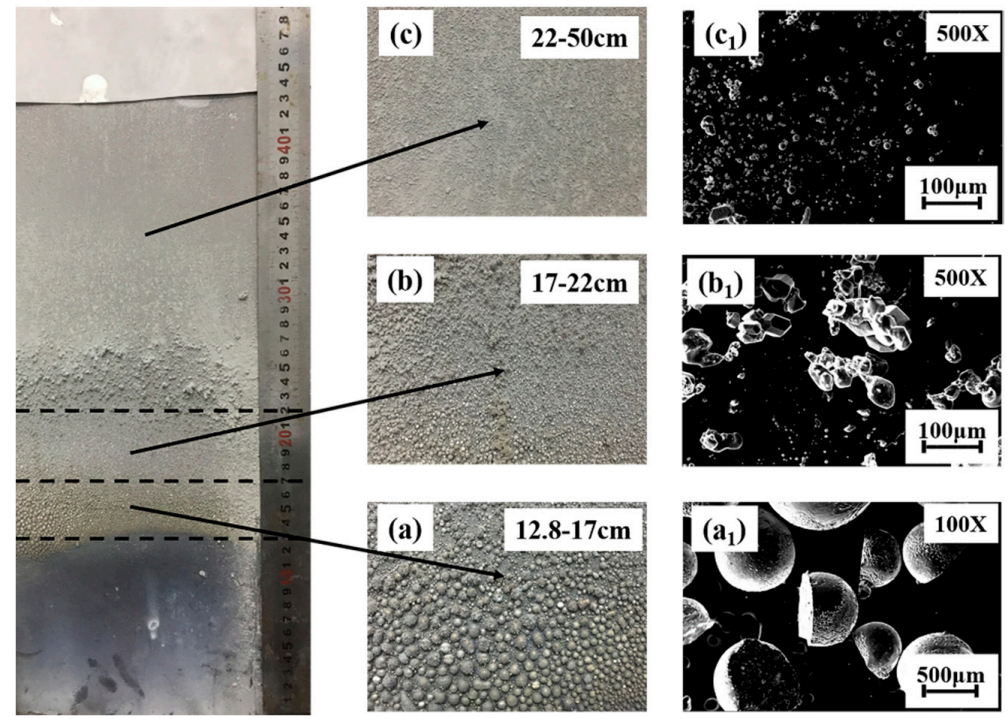

Figure 9. Macroscopic phenomenon of $\mathrm{Mg}$ vapor condensation in different condensation zones (1473 K heating and $0.2 \mathrm{~m}^{3} / \mathrm{h} \mathrm{Ar}$ ): (a) $\mathrm{Mg}$ product at $12.8-18 \mathrm{~cm},(\mathbf{b}) \mathrm{Mg}$ product at $17-22 \mathrm{~cm}$, (c) $\mathrm{Mg}$ product at 22-50 cm, (a $\mathbf{a})$ SEM image of Mg product at $12.8-18 \mathrm{~cm},\left(\mathbf{b}_{1}\right)$ SEM image of $\mathrm{Mg}$ product at $17-22 \mathrm{~cm}$, (c1) SEM image of $\mathrm{Mg}$ product at $22-50 \mathrm{~cm}$.

XRD images of different condensation zones at an Ar flow rate of $0.2 \mathrm{~m}^{3} / \mathrm{h}$ and heat source temperature of $1473 \mathrm{~K}$ were shown in Figure 8 which corresponded to the condensation products in Figure 9. The crystalline morphology of droplet magnesium or powder magnesium had high purity. Magnesium condensation product had a preference for the (101) orientation than others. The preferred orientation did not change with the condensation temperature, which was different from the Xiong's XRD results [25]. Magnesium vapor condensed in vacuum directly by Xiong's experiment, while our experiment was carried out in argon. In our experiment, we considered that it was beneficial to the (101) orientation of magnesium condensation products in the flow of argon of a single direction flow of mixed gas. 
Observation of condensed $\mathrm{Mg}$ vapor on graphite foil at a heat source temperature of $1473 \mathrm{~K}$ and Ar flow rate of $0.2 \mathrm{~m}^{3} / \mathrm{h}$ showed that the $\mathrm{Mg}$ vapor products could be divided into three parts according to the axial distance (Figure 9 with distance and condensation temperature of (a) $12.8-17 \mathrm{~cm}$ and 1013.3-837.4 K, (b) 17-22 cm and 837.4-694.7 K, and (c) 22-50 cm and 694.7-482 K). SEM analyses of the condensation products of the three parts were carried out, which showed that there were significant differences in the $\mathrm{Mg}$ particle sizes in the different regions (Figure 9). In the region of higher temperature condensation, the heat exchange and heat loss of $\mathrm{Mg}$ atoms were relatively small in the collision process with each other and the wall (Figure 9a, $\mathrm{a}_{1}$ ) and the collision number between $\mathrm{Mg}$ atoms in the system was relatively large, which provided the necessary conditions for atomic aggregation and nucleation. At the higher condensation temperatures region, particles were spherical or hemispherical and the liquid particles shrank under the action of surface tension to obtain spherical droplets, with the radius of the spherical condensed $\mathrm{Mg}$ being much larger than the critical nucleation radius at the corresponding temperature. This was caused by the collisions between droplets, which was consistent with the effects of temperature and pressure on the phase deformation process of $\mathrm{Mg}$ atoms. When the temperature of the condensing zone decreased under the forced Ar convection, $\mathrm{Mg}$ atoms moved from the high to low temperature zone before they could nucleate and grow (Figure $9 b, b_{1}, c, c_{1}$ ). There was much heat exchange and heat loss in the collision process between $\mathrm{Mg}$ atoms and the wall, which led to the direct phase transition of $\mathrm{Mg}$ vapor from gas to solid phase. In the process of continuous $\mathrm{Mg}$ vapor evaporation, a large amount of $\mathrm{Mg}$ powder was obtained by condensation in the lower temperature zone, where all kinds of agglomerates came together. Using Equation (1) for calculating the phase diagram of the single metal $\mathrm{Mg}$, when the partial pressure of $\mathrm{Mg}$ vapor was greater than $363.8 \mathrm{~Pa}$, $\mathrm{Mg}$ vapor condensed in line a and the gas-liquid-solid phase transition occurred (Figure 10). If the $\mathrm{Mg}$ vapor condensed below the melting point, the vapor condensed directly from the gas to solid (Figure 10, line b). The condensation zone temperature decreased, and both critical nucleation radius of the atoms and the required nucleation atom number decreased. However, lower temperature would lead to a gas-solid phase transition. For metallic Mg, the gas-solid phase transition would have led to formation of $\mathrm{Mg}$ powder, which easy to combustion or even explosion. Therefore, the minimum condensation zone temperature should be kept higher than $923 \mathrm{~K}$. The closer the temperature of the condensing zone was to $923 \mathrm{~K}$, the fewer atoms were needed for nucleation, which was conducive to gas-liquid phase deformed cores. However, from the experimental results, the blue ellipse line in Figure 10 was the position where $\mathrm{Mg}$ droplets appeared, and the yellow ellipse line was the position where a powdery condensed product appeared. It was seen here in experiments that at 837.4-923 K, there were still $\mathrm{Mg}$ droplets with nucleation and growth. The reason for this could have been that, $\mathrm{Mg}$ vapor was carried to the zone below $923 \mathrm{~K}$ after condensation nucleation occurred in space under the effects of Ar flow, such that there was a difference between the condensation area and the analysis.

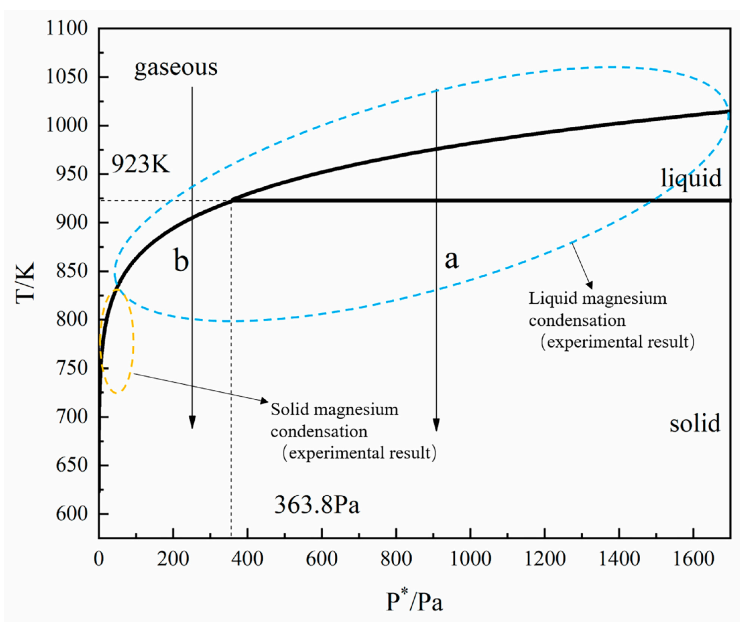

Figure 10. Three-phase diagram and experimental results $\mathrm{Mg}\left(1473 \mathrm{~K}\right.$ heating and $\left.0.2 \mathrm{~m}^{3} / \mathrm{h} \mathrm{Ar}\right)$. 
The mapping scanning and EDS analysis of the corresponding position in Figure 9 were carried out. The results are shown in Figure 11. The $\mathrm{Mg}, \mathrm{C}$ and $\mathrm{O}$ were found in the mapping scanning. $\mathrm{Mg}$ mainly existed in the condensation products (Figure $11 \mathrm{a}_{1}$ ), and the result showed that both large and small particles were mainly composed of $\mathrm{Mg}$. O mainly existed on the surface of magnesium particles (Figure 11 $\mathrm{a}_{2}$ ); the reason was that the magnesium particles were active, was because a small part of magnesium was oxidized, and the presence of $C$ in other positions was due to the basement, which was composed of carbon (Figure $11 \mathrm{a}_{3}-\mathrm{c}_{3}$ ). EDS analysis was carried out on the surface and back of spherical particles with darker color areas. A was the surface of condensed magnesium particles, and B was the back of condensed particles which was the contact surface between condensed and graphite foil. The mass percent of $\mathrm{Mg}$ at points $\mathrm{A}, \mathrm{C}, \mathrm{D}$, and $\mathrm{F}$ were $88.3 \%, 90.9 \%, 88.9 \%$, and $93.7 \%$ shown in Figure 11 and Table 4, respectively. It also contained a small amount of $\mathrm{C}$ and $\mathrm{O}$. The reason for the existence of $C$ is that the graphite foil was used for condenser, and the part of $C$ was bonded during the collection process, while the content of $\mathrm{O}$ was very low. It could be inferred that the particle was mainly composed of $\mathrm{Mg}$, a small amount of $\mathrm{C}$ was attached, and the surface was not oxidized. In the position of $B$ and $E$, the contents of $C$ were $43.7 \%$ and $39.5 \%$ respectively. The source of $C$ was mainly from the surface of condensate and the contact surface of graphite foil, which carried a large amount of $C$. This phenomenon was more common on the back of the spherical surface. The content of $\mathrm{O}$ in $\mathrm{E}$ point was $14.4 \%$, which indicated that some condensed magnesium had been oxidized when the particle sizes were small. However,for all condensation products, the results showed that the product of magnesium vapor condensation was of high purity at heat source temperature of 1273-1473 K and Ar flow rate of $0.1-0.4 \mathrm{~m}^{3} / \mathrm{h}$ and not easily oxidized, which also provides a method for the continuous magnesium vapor condensation process in Ar flow.

It can be seen from the results that the size of the condensed particles in the magnesium vapor decreased with the temperature decreased in the condensation zone, and the condensed products changed from spherical or hemispherical particles to small particles. Due to the high temperature in the condensation zone, the number of collisions increases greatly, which provides the necessary conditions for the aggregation, nucleation, and growth of magnesium atoms. The number of collisions decreased at low temperature, but the nucleation rate increased due to the fact that the radius of nucleation was small. A large amount of magnesium vapor was condensed at the same time, and small particles of condensed magnesium were obtained, which were consistent with the calculation results. When the mixture of gas moved in the tube, the partial pressure of magnesium vapor in the high temperature condensation zone was far greater than the saturated vapor pressure. There were more condensation masses and larger particles. The magnesium vapor condensed continuously at a lower temperature zone, and the partial pressure of the magnesium vapor decreased in the mixed gas. When the partial pressure of the magnesium vapor was close to the saturated vapor pressure, it was not easy to form large particles of condensed magnesium, which was consistent with the analysis of the effect of the partial pressure on the condensation nucleation of the magnesium vapor.

Table 4. EDS analysis results of $\mathrm{Mg}$ vapor condensation in different condensation zones (1473 K heating and $0.2 \mathrm{~m}^{3} / \mathrm{h} \mathrm{Ar}$ ).

\begin{tabular}{ccccc}
\hline \multicolumn{5}{c}{ Composition/(Mass Percent) } \\
\hline No. & Mg & O & C & Ca \\
\hline A & 88.3 & 1.6 & 10.1 & - \\
B & 52.7 & 3.6 & 43.7 & - \\
C & 90.9 & 0.7 & 8.4 & - \\
D & 88.9 & 0.8 & 10.3 & - \\
E & 45.3 & 14.4 & 39.5 & 0.8 \\
F & 93.7 & 0.5 & 5.8 & - \\
\hline
\end{tabular}



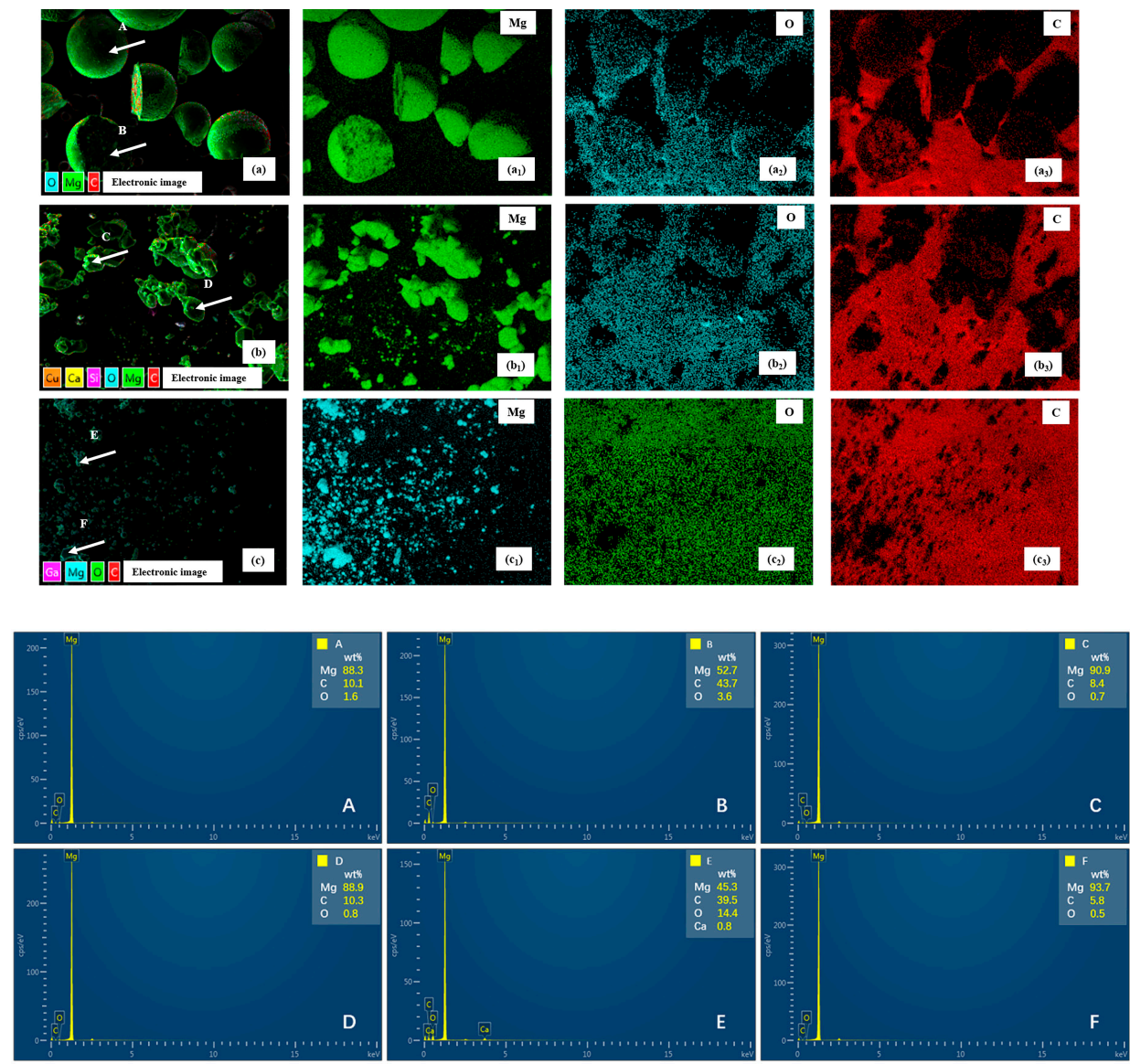

Figure 11. Mapping and EDS of Mg vapor condensation in different condensation zones (1473 K heating and $0.2 \mathrm{~m}^{3} / \mathrm{h} \mathrm{Ar}$ ): (a) Mapping of Mg product at 12.8-17 cm, (b) Mapping of Mg product at $17-22 \mathrm{~cm}$, (c) Mapping of $\mathrm{Mg}$ product at $22-50 \mathrm{~cm},\left(\mathbf{a}_{1}-\mathbf{a}_{3}\right) \mathrm{Mg}, \mathrm{O}$ and $\mathrm{C}$ component of $\mathrm{Mg}$ product at $12.8-18 \mathrm{~cm}$, $\left(\mathbf{b}_{1}-\mathbf{b}_{3}\right) \mathrm{Mg}, \mathrm{O}$ and $\mathrm{C}$ component of $\mathrm{Mg}$ product at $17-22 \mathrm{~cm},\left(\mathbf{c}_{\mathbf{1}}-\mathbf{c}_{3}\right) \mathrm{Mg}, \mathrm{O}$ and $\mathrm{C}$ component of $\mathrm{Mg}$ product at $22-50 \mathrm{~cm} ;(\mathbf{A}-\mathbf{F})$ are EDS analysis results in mapping.

\section{Conclusions}

In this paper, the condensation behavior of $\mathrm{Mg}$ vapor at Ar flow rate of $0.1-0.4 \mathrm{~m}^{3} / \mathrm{h}$ and heat source temperature of 1273-1473 K was studied by theoretical calculation and experiments based on the continuous magnesium production process. The initial condensation temperature of $\mathrm{Mg}$ vapor increased when the heat source temperature increased, which showed that temperature and partial pressure were the key factors for magnesium vapor condensation. The magnesium vapor condensed into liquid state when the heat source temperature and partial pressure were high. The number of collisions, the radius of nucleation, and the number of particles needed for nucleation of magnesium vapor particles were calculated by the homogeneous nucleation theory and the Kelvin equation. When the Mg vapor was in supersaturated, the collision number was greater than the saturated $\mathrm{Mg}$ vapor, which was conducive to the $\mathrm{Mg}$ vapor nucleation formation and growth. The lower the temperature was, the smaller the nucleation radius and the number of atoms required were, which was also conducive to condensation nucleation. However, the gas-solid phase transition was occurred from the phase diagram analysis, which was not conducive to the collection of condensation products when the temperature was lower than $923 \mathrm{~K}$. When the condensation temperature was closer to $923 \mathrm{~K}$, the critical nucleation radius was smaller and the nucleation atoms number was smaller, which was beneficial to the gas-liquid phase transition. The micromorphology results showed that when the condensation zone temperature was more than $837.4 \mathrm{~K}$, droplet condensation products with larger particles were obtained and $\mathrm{Mg}$ powders appeared in the low temperature condensation zone. 
The condensation products obtained here were of high purity. The nucleation rate and crystallization quality of the liquid phase were improved by small temperature gradient and high partial pressure of $\mathrm{Mg}$ vapor.

The experimental results can be used to improve the magnesium production process and design a condenser, in which Ar can be recycled. The nucleation and growth process of magnesium during the condensation process is explained, which provides guidance for the design of magnesium condenser in magnesium production.

Author Contributions: Writing-original draft, J.H.; writing-review and editing, T.Z.; resources, T.Z.; writing-review and editing, D.F.; writing-review and editing, J.G.; writing-review and editing, Z.J.; writing-review and editing, Z.D. All authors have read and agreed to the published version of the manuscript.

Funding: This work was supported by National Natural Science Foundation of China (51504058; U1508217; 51404054; 51374064), the Fundamental Research Funds for the Central Universities of China (N162504003, N140204013), the Fund of Liaoning S and T Project (201601003, LZ2014021).

Acknowledgments: The authors would like to thank Laboratory Center of Northeastern University for analysis.

Conflicts of Interest: The authors declare no conflict of interest.

\section{References}

1. Joost, W.J.; Krajewski, P.E. Towards magnesium alloys for high-volume automotive applications. Scr. Mater. 2016, 128, 107-112. [CrossRef]

2. Karakulak, E. A review: Past, present and future of grain refining of magnesium castings. J. Magnes. Alloys 2019, 7, 355-369. [CrossRef]

3. Fu, D.; Ji, Z.; Guo, J.; Han, J.; Dou, Z.; Liu, Y.; Zhang, T.; Guan, L. Diffusion and phase transformations during the reaction between ferrosilicon and CaO-MgO under vacuum. J. Mater. Res. Technol. 2020, 9, 4379-4385. [CrossRef]

4. Tian, Y.; Xu, B.; Yang, C.; Yang, B.; Qu, T.; Liu, H.; Dai, Y.; Liu, D. Analysis of magnesia carbothermic reduction process in vacuum. Metall. Mater. Trans. B 2014, 45, 1936-1941. [CrossRef]

5. Tian, Y.; Xu, B.; Yang, B.; Yang, C.; Qu, T.; Liu, D.; Dai, Y. Magnesium production by carbothermic reduction in vacuum. J. Magnes. Alloys 2015, 3, 149-154. [CrossRef]

6. Halmann, M.; Frei, A.; Steinfeld, A. Magnesium production by the pidgeon process involving dolomite calcination and $\mathrm{MgO}$ silicothermic reduction: Thermodynamic and environmental analyses. Ind. Eng. Chem. Res. 2008, 47, 2146-2154. [CrossRef]

7. United States Geological Survey. Magnesium Statistics and Information. 2020. Available online: https: //www.usgs.gov/centers/nmic/magnesium-statistics-and-information (accessed on 3 May 2020).

8. Gao, F.; Nie, Z.; Wang, Z.; Gong, X.; Zuo, T. Assessing environmental impact of magnesium production using Pidgeon process in China. Trans. Nonferr. Met. Soc. 2008, 18, 749-754. [CrossRef]

9. Li, R.; Zhang, S.; Guo, L.; Wei, J. Numerical study of magnesium $(\mathrm{Mg})$ production by the Pidgeon process: Impact of heat transfer on Mg reduction process. J. Heat Mass Transf. 2013, 59, 328-337. [CrossRef]

10. Zhang, C.; Wang, C.; Zhang, S.; Guo, L. Experimental and numerical studies on a one-step method for the production of $\mathrm{Mg}$ in the silicothermic reduction process. Int. J. Miner. Process. 2015, 54, 8883-8892. [CrossRef]

11. Zhang, C.; Wang, C.; Zhang, S.; Guo, L. The effects of hydration activity of calcined dolomite (HCD) on the silicothermic reduction process. Int. J. Miner. Process. 2015, 142, 154-160. [CrossRef]

12. Wang, C.; Zhang, C.; Zhang, S.; Guo, L. The effect of $\mathrm{CaF}_{2}$ on the magnesium production with silicothermal process. Int. J. Miner. Process. 2015, 142, 147-153. [CrossRef]

13. Li, R.; Zhang, C.; Zhang, S.; Guo, L. Experimental and numerical modeling studies on production of Mg by vacuum silicothermic reduction of CaO-MgO. Metall. Mater. Trans. B 2014, 45, 236-250. [CrossRef]

14. Fu, D.; Feng, N.; Wang, Y. Study on the kinetics and mechanism of grain growth during the thermal decomposition of magnesite. Bull. Korean Chem. Soc. 2012, 33, 2483-2488. [CrossRef]

15. Fu, D.; Wang, Y.; Peng, J.; Di, Y.; Tao, S.; Feng, N. Mechanism of extracting magenesium from mixture of calcined magnesite and calcined dolomite by vacuum aluminothermic reduction. Trans. Nonferr. Met. Soc. 2014, 24, 2677-2686. [CrossRef] 
16. Fu, D.; Zhang, T.; Guan, L.; Dou, Z.; Wen, M. Magnesium production by silicothermic reduction of dolime in pre-prepared dolomite pellets. JOM 2016, 68, 3208-3213. [CrossRef]

17. Fu, D.; Feng, N.; Wang, Y.; Peng, J.; Di, Y. Kinetics of extracting magnesium from mixture of calcined magnesite and calcined dolomite by vacuum aluminothermic reduction. Trans. Nonferr. Met. Soc. 2014, 24, 839-847. [CrossRef]

18. Fu, D.; Zhang, T.; Dou, Z.; Guan, L. A new energy-efficient and environmentally friendly process to produce magnesium. Can. Metall. Quar. 2017, 56, 418-425. [CrossRef]

19. Morsi, I.M.; Ali, H.H. Kinetics and mechanism of silicothermic reduction process of calcined dolomite in magnetherm reactor. Int. J. Miner. Process. 2014, 127, 37-43. [CrossRef]

20. Morsi, I.M.; Barawy, K.; Morsi, M.B. Abdel-gawad SR. silicothermic reduction of dolomite ore under inert atmosphere. Can. Metall. Quar. 2002, 41, 15-28. [CrossRef]

21. Wulandari, W.; Brooks, G.A.; Rhamdhani, M.A.; Monaghan, B.J. Kinetic analysis of silicothermic process under flowing argon atmosphere. Can. Metall. Quar. 2014, 53, 17-25. [CrossRef]

22. Che, Y.; Hao, Z.; Zhu, J.; Fu, Z.; He, J.; Song, J. Kinetic mechanism of magnesium production by silicothermy in argon flowing. Thermochim. Acta 2019, 681, 178397. [CrossRef]

23. Zhang, T.; Dou, Z.; Zhang, Z.; Liu, Y.; Lv, G.; He, J.C. Method for Smelting Magnesium Quickly and Continuously. U.S. Patent 10047413, 14 August 2018.

24. Yang, C.; Tian, Y.; Qu, T.; Yang, B.; Xu, B.; Dai, Y. Magnesium vapor nucleation in phase transitions and condensation under vacuum conditions. Trans. Nonferr. Met. Soc. 2014, 24, 561-569. [CrossRef]

25. Xiong, N.; Tian, Y.; Yang, B.; Xu, B.; Liu, D.; Dai, Y. Volatilization and condensation behaviours of Mg under vacuum. Vacuum 2018, 156, 463-468. [CrossRef]

26. Xiong, N.; Tian, Y.; Yang, B.; Xu, B.; Dai, T.; Dai, Y. Results of recent investigations of magnesia carbothermal reduction in vacuum. Vacuum 2019, 160, 213-225. [CrossRef]

27. Xiong, N.; Tian, Y.; Chen, X.; Li, K.; Xu, B.; Yang, B.; Dai, Y. Dynamic simulation and experimental study of magnesia formed between magnesium vapor and CO under vacuum. JOM 2019, 71, 2791-2797. [CrossRef]

28. Yang, C.; Tian, Y.; Qu, T.; Yang, B.; Xu, B.; Dai, Y. Production of magnesium during carbothermal reduction of magnesium oxide by differential condensation of magnesium and alkali vapours. J. Magnes. Alloys 2013, 1, 323-329. [CrossRef]

29. Izmailov, A.F.; Myerson, A.S.; Arnold, S. A statistical understanding of nucleation. J. Cryst. Growth 1999, 196, 234-242. [CrossRef]

30. Leubner, I.H. Particle nucleation and growth models. Curr. Opin. Colloid Interface Sci. 2000, 5, 151-159. [CrossRef]

31. Terry, A.R. Nano-sized cluster nucleation. Adv. Colloid Interface Sci. 2001, 91, 473-499.

32. Lummen, N.; Kraska, T. Homogeneous nucleation of iron from supersaturated vapor investigated by molecular dynamics simulation. J. Aerosol Sci. 2005, 36, 1409-1426. [CrossRef]

33. Hischier, I.; Chubukov, B.A.; Wallace, M.A.; Fisher, R. A novel experimental method to study metal vapor condensation/oxidation: $\mathrm{Mg}$ in $\mathrm{CO}$ and $\mathrm{CO}_{2}$ at reduced pressures. Sol. Energy 2016, 139, 389-397. [CrossRef]

34. Dai, Y. Vacuum Metallurgy of Nonferrous Metals; Metallurgical Industry: Beijing, China, 2000.

35. Haynes, W.M. CRC Handbook of Chemistry and Physics; CRC Press: Boca Raton, FL, USA, 2017.

36. Zhang, R.; Khalizov, A.; Wang, L.; Hu, M.; Xu, W. Nucleation and growth of nanoparticles in the atmosphere. Chem. Rev. 2012, 112, 1957-2011. [CrossRef]

37. Xu, Z. Material Thermodynamics; Higher Education Press: Beijing, China, 2009.

38. Tadros, T. Encyclopedia of Colloid and Interface Science; Springer: Berlin, Germany, 2013.

39. Bohdansky, J.; Schins, H. Surface tension and density of the liquid earth alkaline metals $\mathrm{Mg}, \mathrm{Ca}, \mathrm{Sr}, \mathrm{Ba}$. J. Inorg. Nucl. Chem. 1968, 30, 2331-2337. [CrossRef]

40. Mcgonigal, P.J.; Kirshenbaum, A.D.; Grosse, A.V. The liquid temperature range, density, and critical constants of magnesium. J. Phys. Chem. 1962, 66, 737-740. [CrossRef]

Publisher's Note: MDPI stays neutral with regard to jurisdictional claims in published maps and institutional affiliations. 